\title{
Identification of On-Surface Reaction Mechanism by Targeted Metalation
}

\author{
Alexandra Rieger, Stephan Schnidrig, Benjamin Probst, Karl-Heinz Ernst, and Christian Wäckerlin
}

J. Phys. Chem. C, Just Accepted Manuscript • DOI: 10.1021/acs.jpcc.7b10019 • Publication Date (Web): 21 Nov 2017

Downloaded from http://pubs.acs.org on November 29, 2017

\section{Just Accepted}

"Just Accepted" manuscripts have been peer-reviewed and accepted for publication. They are posted online prior to technical editing, formatting for publication and author proofing. The American Chemical Society provides "Just Accepted" as a free service to the research community to expedite the dissemination of scientific material as soon as possible after acceptance. "Just Accepted" manuscripts appear in full in PDF format accompanied by an HTML abstract. "Just Accepted" manuscripts have been fully peer reviewed, but should not be considered the official version of record. They are accessible to all readers and citable by the Digital Object Identifier (DOI®). "Just Accepted" is an optional service offered to authors. Therefore, the "Just Accepted" Web site may not include all articles that will be published in the journal. After a manuscript is technically edited and formatted, it will be removed from the "Just Accepted" Web site and published as an ASAP article. Note that technical editing may introduce minor changes to the manuscript text and/or graphics which could affect content, and all legal disclaimers and ethical guidelines that apply to the journal pertain. ACS cannot be held responsible for errors or consequences arising from the use of information contained in these "Just Accepted" manuscripts. 


\title{
Identification of On-Surface Reaction Mechanism by Targeted Metalation
}

Alexandra Rieger ${ }^{\dagger}$, Stephan Schnidrig ${ }^{*}$, Benjamin Probst ${ }^{+}$, Karl-Heinz Ernst ${ }^{\dagger, *}$, Christian Wäckerlin ${ }^{\dagger, *}$

\author{
AUTHOR ADDRESS \\ ${ }^{\dagger}$ Empa, Swiss Federal Laboratories for Materials Science and Technology, 8600 Dübendorf, \\ Switzerland \\ $\$$ Institut für Chemie, Universität Zürich, 8057 Zürich, Switzerland
}

\begin{abstract}
Chemical reactions occurring on surfaces may provide an alternate route to materials beyond traditional methods, e.g. large polymers or compounds that would react further in ambient conditions or lack solubility. Many on-surface reactions yield atomic hydrogen which then desorbs swiftly from noble metals of group $11(\mathrm{Cu}, \mathrm{Ag}, \mathrm{Au})$. Using a porphyrin-related macrocycle, so-called pyrphyrin, also bearing two cyano groups at the periphery, we show that dehydrogenation of the center of the macrocycle leads to selective formation of hydrogen cyanide, created from the rim-cyano groups and the hydrogen of the center imine $(=\mathrm{NH})$. Formally, the surface-remaining reaction product is a dicarbene, bearing two divalent carbon atoms. It reacts readily with Fe atoms at room temperature, unlike its pyrphyrin precursor, which requires annealing for metalation with Fe. The hydrogen cyanide abstraction becomes suppressed when pyrphyrin is metalated with iron atoms, because the absence of the two hydrogen atoms does not allow the tautomerization.
\end{abstract}




\section{Introduction}

Many on-surface reactions, such as metalation of porphyrins or cyclodehydrogenation, involve the abstraction of hydrogen. ${ }^{1-10}$ Because the activation barrier for desorption of atomic hydrogen on noble metal surfaces is low, e.g. $23 \mathrm{~kJ} \mathrm{~mol}^{-1}$ for $\mathrm{Ag}(111),{ }^{11}$ it is generally considered to desorb quickly and to be largely irrelevant for further on-surface chemistry. Notably, the thermally activated exchange of carbon-bound fluorine with hydrogen ${ }^{10}$ and of carbon-bound hydrogen with deuterium ${ }^{12}$ was recently observed. Also, atomic hydrogen produced by cyclodehydrogenation was found to be the rate limiting step for bromine desorption. ${ }^{13}$

Scanning tunneling microscopy (STM), in combination with methods like X-ray photoelectron spectroscopy (XPS) and thermal desorption spectroscopy (TDS), allows identification of adsorbates and desorption products as well as investigating structural changes or 2D polymerization. ${ }^{14-16}$ Here we present a study of the on-surface chemistry of pyrphyrin (2HPyr) on a $\operatorname{Ag}(111)$ surface. Specifically, hydrogen atoms from the $=\mathrm{NH}$ imine group in the center of the macrocycle enable at first a tautomerization shift, so that these $\mathrm{H}$ atoms become located next to cyano groups at the rim of the macrocycle, followed by thermally-induced HCN formation (Scheme 1). The produced tetraaza macrocycle (AgTA) is formally a carbene species, most likely stabilized by its direct interaction with the silver surface. ${ }^{17}$ Metalation of $2 \mathrm{HPyr}$ with Fe to FePyr, on the other hand, causes dehydrogenation in the center of the macrocycle at a lower temperature. Consequently, no hydrogen is available for tautomerization and HCN formation is suppressed.

Scheme 1. Reaction pathways of pyrphyrin (2HPyr) annealed on $\operatorname{Ag}(111)$ in presence and absence of trace amounts of Fe. 

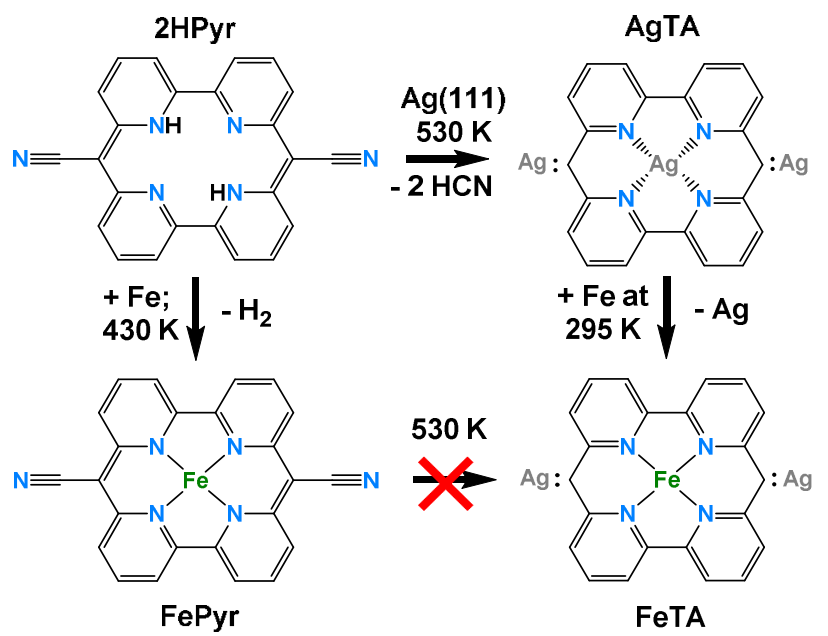

In absence of iron atoms on the surface 2HPyr loses two HCN molecules upon annealing and turns into AgTA, formally a dicarbene. Both the nitrogens in the center and presumably also the carbene carbons interact with silver atoms of the surface. AgTA is transformed into FeTA by atom exchange when $\mathrm{Fe}$ is added at room temperature. Starting from $2 \mathrm{HPyr}$ in presence of Fe, however, annealing is required to achieve metalation to FePyr. The absence of the two hydrogen atoms in the macrocycle in FePyr suppresses scission of its cyano groups and therefore transformation into FeTA.

\section{Methods}

The experiments were conducted in ultra-high vacuum with a base pressure of $5 \times 10^{-10}$ mbar. The $\mathrm{Ag}(111)$ surface was cleaned by cycles of $\mathrm{Ar}^{+}$sputtering and annealing to $673 \mathrm{~K}$. $2 \mathrm{HPyr}$ was purified by resublimation in vacuum and was sublimated from a Knudsen cell kept at $626 \mathrm{~K}$ on the sample kept at RT. Unless specified otherwise, all annealing steps have been performed for $10 \min$.

XPS (Specs PHOIBOS 100 electron analyzer) measurements were conducted with nonmonochromatic $\mathrm{Al} \mathrm{K}_{\alpha}$ X-rays in normal emission. The binding energy scale was calibrated using the $\operatorname{Ag} 3 \mathrm{~d}_{5 / 2}$ signal $(368.3 \mathrm{eV})$ and the Fermi level $(0.0 \mathrm{eV})$ of the crystal. The intensity of the 
spectra was normalized with respect to the intensity of the $\operatorname{Ag} 3 \mathrm{~d}_{5 / 2}$ signal. The background obtained on the clean $\operatorname{Ag}(111)$ crystal was subtracted from the C1s and N1s spectra. To determine the peak areas, a polynomial background plus Shirley step was fitted. The used measurement parameters yielded a FWHM of $1.2 \mathrm{eV}$ for in-situ grown graphene/Cu(111) (a narrow C1s reference). The XP spectra were deconvoluted with symmetric Voigt functions with fixed widths (Gaussian FWHM: $0.9 \mathrm{eV}$, Lorentian FWHM: $0.7 \mathrm{eV}$ ). STM images were taken in constant current mode with a Specs Aarhus 150 instrument using a mechanically cut and in-situ sputtered PtIr (90\% Pt) tip at $295 \mathrm{~K}$, unless specified otherwise. The imaging conditions (bias voltage, current set-point, temperature) are provided in Table S1. The STM images were processed with the WSxM software. ${ }^{18}$ TDS was recorded using a quadrupole mass spectrometer (Balzers QME 200). The mass spectrometer was installed in a special housing with a pinhole to avoid collecting material desorbing from the sample holder.

\section{Results and Discussion}

Figure 1a shows an STM image of the closed packed monolayer 2HPyr on Ag(111). After annealing at temperatures in the range of $400 \mathrm{~K}$ to $570 \mathrm{~K}$, an increasing number of molecules appear darker than the non-annealed species (Figure 1b). The abundance of dark appearing molecules increases to $\sim 80 \%$ after annealing at $\sim 560 \mathrm{~K}$ (Figure 1e). Large-scale images of $1 \mathrm{ML}$ of $2 \mathrm{HPyr}$ on $\mathrm{Ag}(111)$ are presented in Figure S1. In all cases the samples were essentially covered with self-assembled arrays of square-appearing molecules. This confirms that the starting material as well as the annealed samples consist of well-defined molecules and that the macrocycle is not broken. Small patches of mobile molecules were observed in particular if the coverage was slightly below $1 \mathrm{ML}$. 
X-ray photoelectron spectroscopy (XPS) of the N1s region of 1 ML of 2HPyr deposited on $\operatorname{Ag}(111)$ kept at room temperature (RT, $295 \mathrm{~K}$ ) (Figure 1c) reveals a double peak characteristic for free-base macrocycles of porphyrins, ${ }^{19,20}$ phthalocyanines ${ }^{21}$ and pyrphyrin. ${ }^{22-24}$ Pyrphyrin has three non-equivalent nitrogen species, but due to the similar chemical shifts of the cyano nitrogen $(-\mathrm{CN}, 398.8 \mathrm{eV})$ and the iminic nitrogen $(=\mathrm{N}-, 399.1 \mathrm{eV})$, only two peaks are observed. $^{22,23}$ The pyridinic nitrogen $(-\mathrm{NH}-)$ is found at $400.8 \mathrm{eV} \cdot{ }^{22,23}$ Very similar spectra are observed for 3 ML 2HPyr on $\operatorname{Ag}(111)$ (Figure S2). After annealing to $527 \mathrm{~K}$ (10 min) only one peak at $398.4 \mathrm{eV}$ with a reduced intensity is observed. The reduced peak intensity implies that the cyano groups (1/3 of the spectral weight) have been desorbed. The absence of a signal around $400.8 \mathrm{eV}(-\mathrm{NH}-)$ shows that the pyridinic nitrogens have been fully deprotonated, as it is observed in case of a metalation reaction. ${ }^{4,25}$ Metalation with silver has been observed for tetrapyrrols on Ag surfaces. ${ }^{26-29}$ The N1s binding energy of the nitrogens in the macrocycle (398.4 eV) is consistent with $\mathrm{N}-\mathrm{Ag}$ in Ag-phthalocyanine obtained by metalation on $\mathrm{Ag}(110)^{26}$ and significantly lower than for $\mathrm{N}-\mathrm{Cu}$ in $\mathrm{Cu}-$ pyrphyrin/ $\mathrm{Cu}(111) .{ }^{23}$ Due to the small size of the pyrphyrin macrocycle, it is unlikely that a Ag adatom penetrates the macrocycle and is coordinated exactly in the molecular plane. Presumably, is weakly coordinated somewhat below the molecular plane.

The corresponding C1s XPS spectra (Figure S3) reveal line shapes which are consistent with the identified species based on N1s signals. In particular after annealing, the spectral weight around $286.5 \mathrm{eV}(-\mathrm{CN})$ is reduced while at the same time a component at low binding energy (284.3 eV) appears ( $c f$. difference spectra in Figure 1d). Such C1s XP signals at low binding energies are characteristic for $\mathrm{C}-\mathrm{Ag}^{5}$ or $\mathrm{C}-\mathrm{Cu}^{30}$ species. The exact binding energies of all peak components are reported in Table S2. The C / $\mathrm{N}$ ratio, calibrated with respect to the $2 \mathrm{HPyr}$ 
sample, of 4.86 , corresponds to $58 \%$ of AgTA. This value agrees very well with the abundance of dark molecules observed by STM (Figure 1e). The carbon and nitrogen intensities and the calculated $\mathrm{C} / \mathrm{N}$ ratios are reported in Table S3. Since all nitrogens in the macrocycle are deprotonated (absent - NH- signal) but not all molecules appear dark, the native appearing molecules correspond to 2HPyr and AgPyr. A model, where only one CN group per molecule is desorbed, would yield an abundance greater than unity and can therefore be excluded (Figure S4). Thus, we identify the species of dark appearing molecules in STM as AgTA, which is pyrphyrin minus two HCN. The sublimation of $\sim 1$ Fe atom per molecule leads to an upshift of the binding energy to $399.25 \mathrm{eV}$. The higher binding energy is consistent with $\mathrm{N}-\mathrm{Fe}$ in $\mathrm{Fe}-$ phthalocyanine on $\operatorname{Ag}(111)^{21}$ and with $\mathrm{N}-\mathrm{Co}$ in Co-pyrphyrin ${ }^{22,24}$ and can be related to the stronger N-metal interaction. ${ }^{31}$ Thus, it shows that weakly coordinated Ag to the macrocycle is exchanged with Fe, i.e. the transformation of AgTA to FeTA.
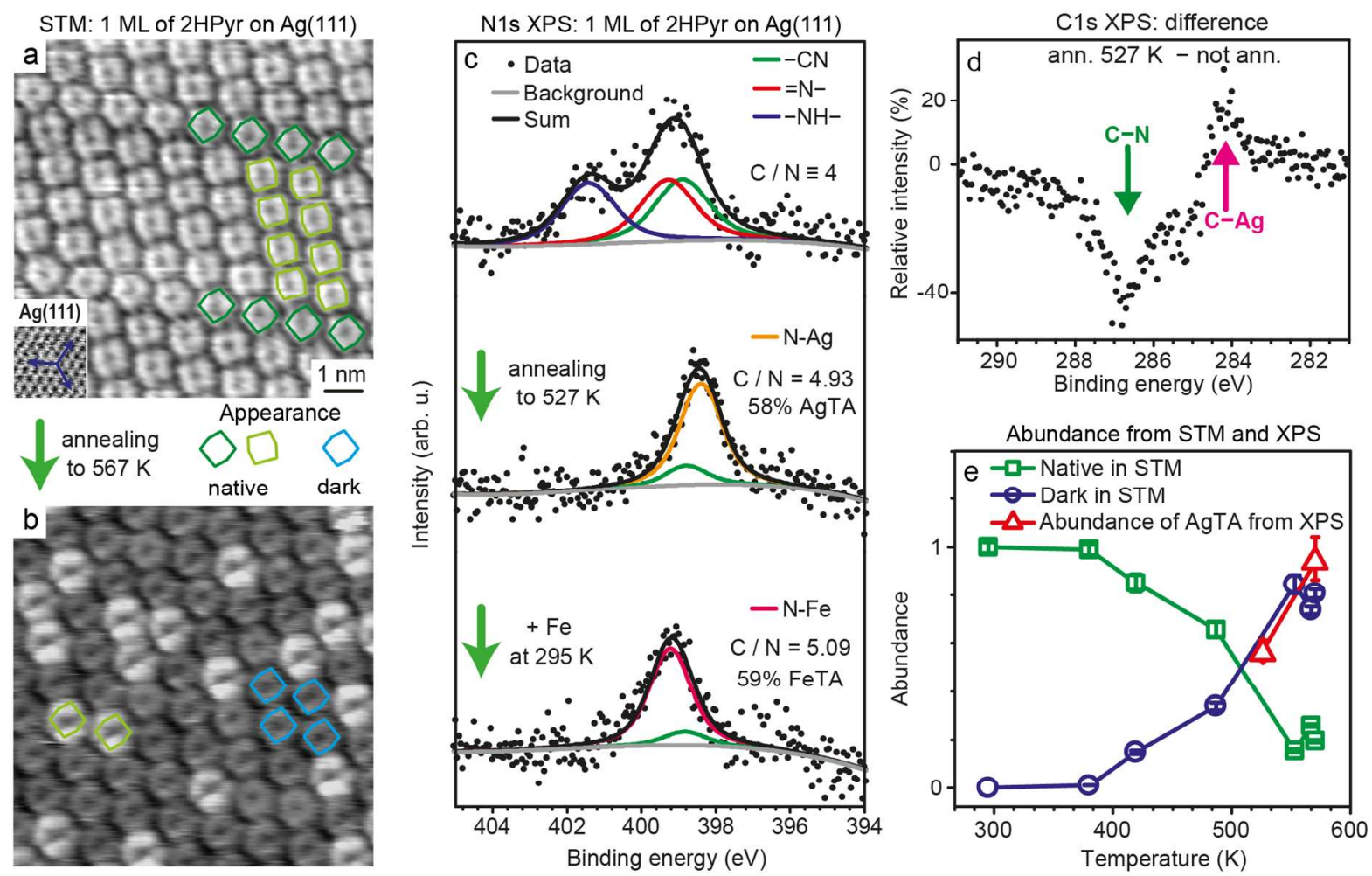
Figure 1 STM images and XP spectra of 1 ML of 2HPyr before and after annealing. (a) STM image obtained before annealing, showing identical appearance of all molecules. In some rows, the molecules are rotated with respect to other rows. The inset displays atomic resolution on $\operatorname{Ag}(111)$. (b) The STM image acquired after annealing shows a majority of darker appearing molecules. (c) The N1s XP spectrum of 2HPyr reveals a double peak line shape. After annealing, the N1s XP spectrum reveals only one peak with reduced intensity and an increased C / N ratio. The addition of $\mathrm{Fe}$ atoms on the sample kept at room temperature results in an upshift of the N1s XP signal by $0.85 \mathrm{eV}$. This is evidence for prompt replacement of $\mathrm{Ag}$ with $\mathrm{Fe}$, i.e. transformation from AgTA to FeTA. The residual spectra are shown in Figure S5. (d) In the difference spectra of the $\mathrm{C} 1 \mathrm{~s}$ region, i.e. the spectra obtained after annealing to $527 \mathrm{~K}$ minus the spectra of $2 \mathrm{HPyr}$, a decreased spectral weight around $286.5 \mathrm{eV}$ and increased intensity around $284.3 \mathrm{eV}$ is observed. (e) Abundance of dark molecules seen in STM and the abundance of AgTA calculated from the $\mathrm{C} / \mathrm{N}$ ratio versus temperature.

If $1 \mathrm{ML}$ of $2 \mathrm{HPyr}$ is annealed in presence of $\sim 1 \mathrm{Fe}$ atom per molecule, different $\mathrm{XP}$ spectra compared to the abovementioned case (1 ML of 2HPyr annealed on $\mathrm{Ag}(111)$ without Fe) are observed (Figure 2). First, the N1s intensity is not reduced. Second, the experimental data is consistent with two components which are Fe bound nitrogen $(399.25 \mathrm{eV})$ in the macrocycle and cyano-N (398.8 eV). The same has been observed in N1s XP spectra acquired from in-situ synthesized $\mathrm{CoPyr}^{22}$ and $\mathrm{CuPyr}^{23}$. Third, the $\mathrm{C} / \mathrm{N}$ reveals that the cyano groups are not removed. Specifically, its value of 4.06 corresponds to $96 \%$ of (metallo-)pyrphyrin. This species is identified as FePyr, consistent with STM data (see below). Annealing to $527 \mathrm{~K}$ (10 min) in a second step leads to only very small changes in the N1s and C1s line shapes or intensities, evidencing that FePyr is not converted to FeTA. In both cases, the corresponding $\mathrm{C} 1 \mathrm{~s}$ spectra 
(Figure S3) are also compatible with pyrphyrin, in particular the low binding energy component observed for AgTA and FeTA is not present.

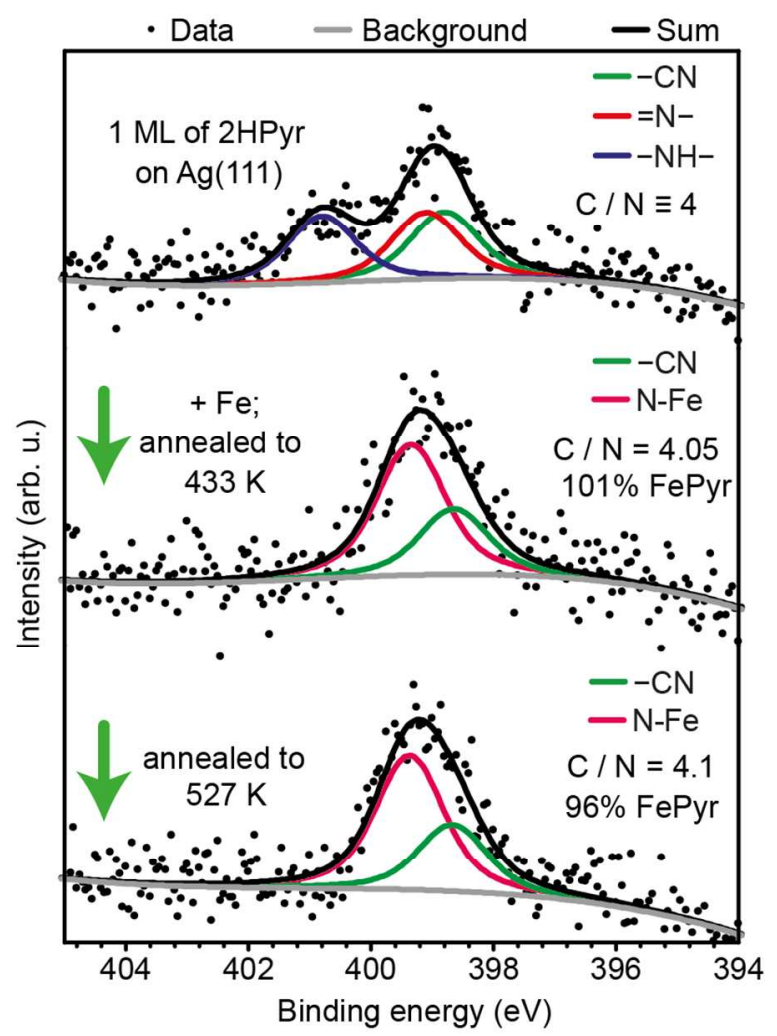

Figure 2: N1s XP spectra of $1 \mathrm{ML}$ of $2 \mathrm{HPyr}$ on $\mathrm{Ag}(111)$ annealed in presence of $\sim 1.04 \mathrm{Fe}$ atoms per molecule. After annealing to $433 \mathrm{~K}$, the double peak line shape of $2 \mathrm{HPyr}$ is replaced by a narrower N1s signal with identical intensity and $\mathrm{C} / \mathrm{N}$ ratio, corresponding to FePyr. The residual spectra are shown in Figure S5.

Our STM study of samples containing a mixture of $2 \mathrm{HPyr}$ and AgTA $(0 \%, 34 \%$ and $74 \%$ of AgTA), each exposed to increasing amounts of $\mathrm{Fe}$ (up to $\sim 1 \mathrm{Fe}$ atoms per molecule) at room temperature, reveals higher degrees of metalation with increasing abundance of AgTA (Figure 3). In case of pure 2HPyr (Figure 3a,d,g), sublimation of Fe leads mainly to Fe-cluster formation. 
No change is observed even after keeping the sample at room temperature for several hours (Figure S6). A small amount of molecules appearing bright in their centers is observed, we attribute these to metalated or intermediately metalated molecules. ${ }^{22,32}$ The term "intermediately metalated" refers to molecules where the metal atom is situated on top of a pyridine ring of $2 \mathrm{HPyr}^{22,32}$ Such molecules appear with an asymmetric protrusion. We observe such appearance predominantly in samples with high abundance of 2HPyr (Figure S6). Note that some directly metalated molecules with symmetric appearance are also found in pure $2 \mathrm{HPyr}$ samples, which suggests that the approaching Fe atom is directly incorporated to some degree. ${ }^{33}$ Mild annealing $(433 \mathrm{~K}, 1 \mathrm{~h})$ leads to the case that all molecules appear bright and symmetric, i.e. complete metalation to FePyr (Figure S7). A very similar behavior has been observed for the metalation of 2HPyr on $\mathrm{Au}(111)$ with Co. ${ }^{22}$

Adding Fe to the sample containing 34\% of AgTA leads to fewer clusters and significantly more bright (i.e. metalated) molecules (Figure 3b,e,h). For the 74\% of AgTA, only a couple of clusters are observed and almost complete metalation is achieved at room temperature (Figure 3c,f,i). The abundance of native (2HPyr and AgPyr), bright (FeTA and FePyr) and dark (AgTA) molecules is summarized in Figure 3j-1. A rapid decline of the abundance of AgTA upon Fe addition is observed. So far, atom exchange has been observed for Co and Ni tetrapyrrols at $\mathrm{Cu}(111)$ surfaces in vacuum only at elevated temperatures. ${ }^{33,34}$ Again, the rapid exchange of Ag with Fe observed here can be rationalized with silver being only weakly coordinated (presumably situated below the macrocycle due to its size). Therefore it is easily expelled in favor of the Fe coordination. 

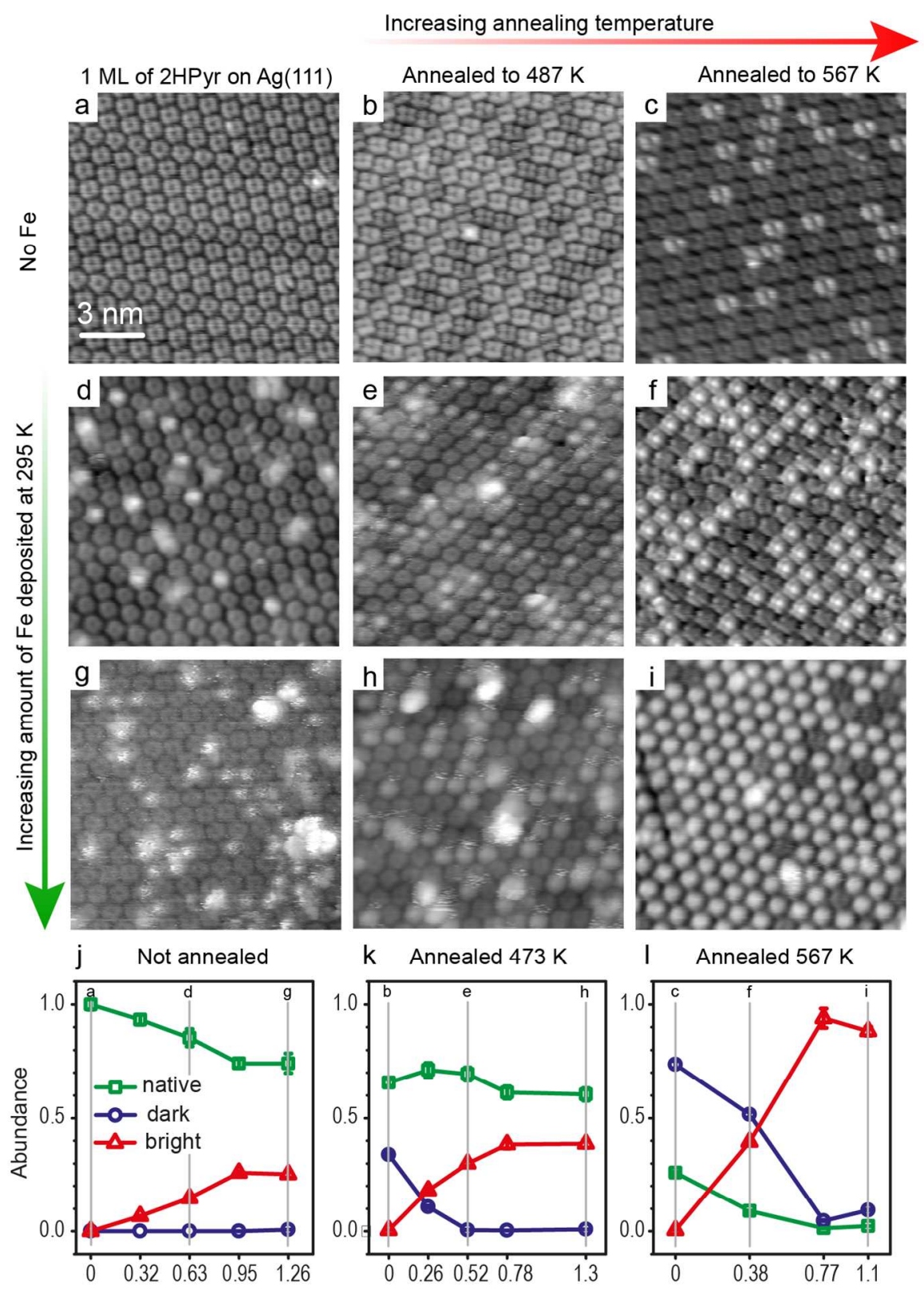

K Annealed $473 \mathrm{~K}$ I Annealed $567 \mathrm{~K}$
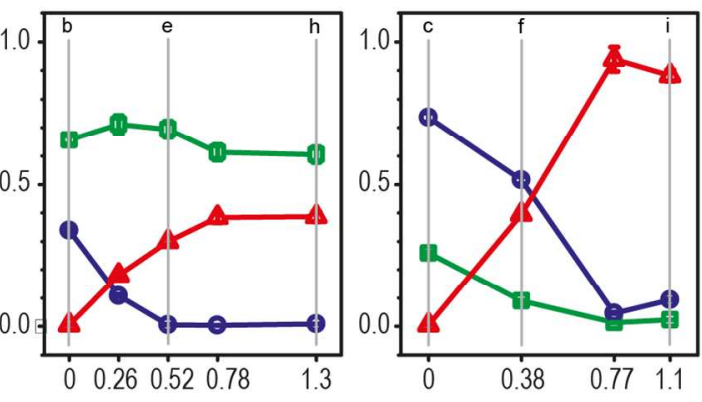

$\mathrm{Fe}$ atoms per molecule

Figure 3. a) STM images of $1 \mathrm{ML}$ of $2 \mathrm{HPyr}$ on $\mathrm{Ag}(111)$ annealed to different temperatures to produce different abundances of native and dark appearing molecules (a-c). Increasing amounts of Fe are deposited on the sample kept at RT (d-i). The scale bar applies to all STM images. All images shown are obtained at approximately $-1.2 \mathrm{~V}$ bias voltage. $\mathrm{j}-1)$ Abundance of native 
(2HPyr and AgPyr), dark (AgTA) and bright (metalated and intermediate metalated) appearing molecules.

The most important of the above discussed results is that $2 \mathrm{HPyr}$ on $\mathrm{Ag}(111)$ loses its two hydrogens in the macrocycle and also its two cyano groups upon annealing, forming AgTA. However, if $2 \mathrm{HPyr}$ is first metalated with Fe to FePyr, its cyano groups remain. $m / z=2\left(\mathrm{H}_{2}\right)$ and $m / z=27(\mathrm{HCN})$ desorption spectra for $2 \mathrm{HPyr}$ on $\operatorname{Ag}(111)$ with and without Fe are shown in Figure 4. For 2HPyr on $\mathrm{Ag}(111)$, two maxima are observed for desorbing HCN, but only one for desorbing $\mathrm{H}_{2}$. Specifically, the first maximum $(\boldsymbol{\alpha}, 550 \mathrm{~K})$ is observed in the HCN signal but not in the $\mathrm{H}_{2}$ signal. The second maximum $(\boldsymbol{\beta}, 620-630 \mathrm{~K})$ is found in both $\mathrm{HCN}$ and $\mathrm{H}_{2}$ signals. This $\boldsymbol{\beta}$ peak, reflecting the process in which both $\mathrm{H}_{2}$ and $\mathrm{HCN}$ are produced, is due to the thermal decomposition of the molecules. ${ }^{35,36}$ Consequently, the first maximum $(\boldsymbol{\alpha}, 550 \mathrm{~K})$ is assigned to the scission of the cyano groups from the molecule and to their desorption as HCN, consistent with the formation of AgTA after annealing to $527 \mathrm{~K}$ for $10 \mathrm{~min}$. In view of the TD spectra, minor decomposition might occur as a side reaction at $527 \mathrm{~K}$ (XP spectra). This is consistent with the slightly stronger decrease of the $\mathrm{C} 1 \mathrm{~s}$ intensity compared to the expected decrease (2 of 24 carbon atoms). However, the decrease of the $\mathrm{C} 1 \mathrm{~s}$ intensity can also be due to minor desorption of molecules. Importantly, since STM (Figure S1) shows predominantly extended arrays of molecules with square appearance, most macrocycles remain intact.

In presence of Fe, only one TD maximum $(\boldsymbol{\beta},, 600 \mathrm{~K})$ is observed. The $\boldsymbol{\alpha}$ peak $(\mathrm{CN}$ scission $)$ is absent, consistent with the constant N1s intensity after annealing to $527 \mathrm{~K}$ for $10 \mathrm{~min}$. The decreased temperature for decomposition with Fe ( $\boldsymbol{\beta}$ ' vs. $\boldsymbol{\beta})$ could be caused by the catalytic activity of not reacted Fe or by a slightly lower thermal stability of FePyr. Note that, in contrast to TDS data for the metalation of $2 \mathrm{HPyr}^{23}$ and $2 \mathrm{H}$-porphyrin ${ }^{12}$ with $\mathrm{Cu}$ atoms from the $\mathrm{Cu}(111)$ 
surface, no distinct peak in the $\mathrm{H}_{2}$ spectrum can be found for the metalation with Fe. Presumably, the metalation rate of $2 \mathrm{HPyr}$ with heteroatoms is limited by diffusion of the metal atoms ${ }^{22}$ leading to a broad $\mathrm{H}_{2}$ TD signal. Cyanogen $(\mathrm{CN})_{2}$ was not observed. ${ }^{37}$ Note that the gradual monotonic increase of the $\mathrm{H}_{2}$ TD signals (i.e. not the peaks) is due to a general increase of the partial pressure due to warming-up of the sample holder.

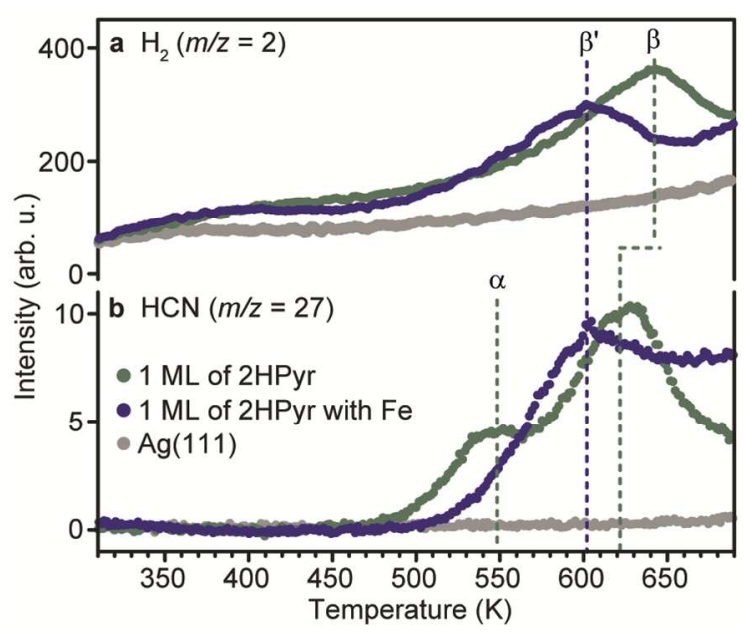

Figure 4. Thermal desorption spectra for hydrogen $\left(\mathrm{H}_{2}, m / z=2\right)$ (a) and hydrogen cyanide (HCN, $m / z=27$ ) (b) obtained from 1 ML of 2HPyr on Ag(111), 1 ML of 2HPyr on Ag(111) with $\sim 1.25 \mathrm{Fe}$ atom per molecule and clean $\mathrm{Ag}(111)$. For $2 \mathrm{HPyr}$, two maxima ( $\boldsymbol{\alpha}$ and $\boldsymbol{\beta}$ ) are observed in the $\mathrm{HCN}$ signal and one maximum $(\boldsymbol{\beta})$ in the $\mathrm{H}_{2}$ signal. For $2 \mathrm{HPyr}$ with $\mathrm{Fe}$, only one maximum $\left(\boldsymbol{\beta}^{\prime}\right)$ is observed in both the $\mathrm{HCN}$ and the $\mathrm{H}_{2}$ signals. The heating rate is $0.6 \mathrm{~K} \mathrm{~s}^{-1}$.

\section{Conclusions}

The on-surface transformation of porphyrin-related pyrphyrin (2HPyr) molecules on $\mathrm{Ag}(111)$ has been studied at monolayer coverages. In STM an increased abundance of dark appearing molecules is observed with increasing annealing temperature. XPS shows that annealing to 530 $\mathrm{K}$ leads to dehydrogenation of its pyridinic nitrogen, which is possible because of stabilization of 
the macrocycle by interaction with Ag and it leads to the loss of both its cyano groups. TD spectra show that the cyano groups desorb as hydrogen cyanide $(\mathrm{HCN})$ at $550 \mathrm{~K}$. The result is the formal di-carbene tetraaza macrocycle AgTA.

In contrast, if trace amounts of Fe atoms are added to $2 \mathrm{HPyr}$, the metalation of the molecule with Fe happens after annealing to $433 \mathrm{~K}$, i.e. FePyr. The cyano groups are not dissociated after annealing to $530 \mathrm{~K}$. Consistently, no HCN desorption maximum is observed at $550 \mathrm{~K}$.

This distinct affinity of $2 \mathrm{HPyr}$ for $\mathrm{HCN}$ elimination and the inertness of FePyr can be rationalized by tautomerization ${ }^{38}$ into a form where the two hydrogens of the macrocycle are attached to the two carbon atoms where the cyano groups are bonded to (Scheme 2). This tautomeric form then facilitates the dissociation of the cyano groups as hydrogen cyanide (HCN). In addition, the rationale explains why FePyr, where the pyridinic hydrogen is missing, is stable at $527 \mathrm{~K}$. The fact that the decyanation does not occur during Fe metalation may indicate that the tautomeric form is not yet thermally accessible at this lower temperature.

\section{Scheme 2. Tautomerization of $2 \mathrm{HPyr}$ facilitating the formation of $\mathrm{HCN}$.}

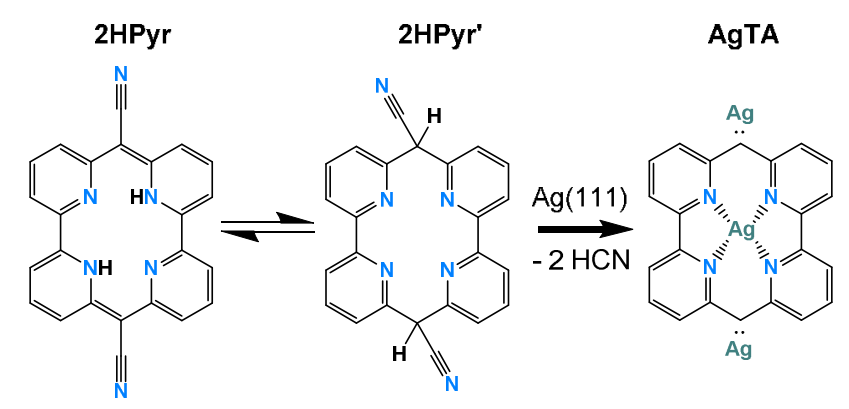

The two hydrogens of the pyridinic nitrogens tautomerize to the two cyano-bound carbons (2HPyr to 2HPyr'). This tautomer enables the dissociation of the cyano groups as hydrogen cyanide $(\mathrm{HCN})$. This selective reaction results in the formal di-carbene tetraaza macrocycle AgTA stabilized by weak coordination to Ag atoms. 
The tetraaza macrocycles AgTA and FeTA, which are formally di-carbene species, are potential intermediates towards the coupling with a second chemical entity. ${ }^{39}$ Although the dicarbene should interact with $\mathrm{Ag}$ adatoms or by direct bonding to an atom in the surface, ${ }^{17,40}$ it could still remain a highly reactive species enabling access to the rich chemistry of carbenes. ${ }^{41} \mathrm{~A}$ direct polymerization though between carbene molecules is sterically blocked by $\mathrm{C}-\mathrm{H}$ repulsion, thereby enabling for very specific on-surface chemistry.

ASSOCIATED CONTENT

\section{Supporting Information.}

The Supporting Information is available free of charge on the ACS Publications website at DOI: [DOI].

Complete tunneling conditions for all STM images, N1s and C1s XPS of 3 ML of 2HPyr, C1s

XPS corresponding to the shown N1s spectra, residual N1s XP spectra, relative C1s and N1s intensities, comparison of C / N models for XP data, N1s peak components, additional STM images including large scale images (PDF).

AUTHOR INFORMATION

Corresponding Author

* E-Mail: christian.waeckerlin@empa.ch

\section{Author Contributions}

The manuscript was written through contributions of all authors. All authors have given approval to the final version of the manuscript.

\section{Notes}


The authors declare no competing financial interest.

\section{ACKNOWLEDGMENT}

Financial support by the University Research Priority Program LightChEC of the University of Zürich, Switzerland, the Swiss National Science Foundation (R'Equip and Grant 200021_152559), and the Competence Centre for Materials Science and Technology (CCMX) is gratefully acknowledged. We thank J. Li, W. Auwärter, J. Osterwalder and R. Alberto for fruitful discussions.

\section{REFERENCES}

(1) Lingenfelder, M. A.; Spillmann, H.; Dmitriev, A.; Stepanow, S.; Lin, N.; Barth, J. V.; Kern, K. Towards Surface-Supported Supramolecular Architectures: Tailored Coordination Assembly of 1,4-Benzenedicarboxylate and $\mathrm{Fe}$ on $\mathrm{Cu}(100)$. Chem. - Eur. J. 2004, 10, 1913-1919.

(2) Cai, J.; Ruffieux, P.; Jaafar, R.; Bieri, M.; Braun, T.; Blankenburg, S.; Muoth, M.; Seitsonen, A. P.; Saleh, M.; Feng, X.; et al. Atomically Precise Bottom-up Fabrication of Graphene Nanoribbons. Nature 2010, 466, 470-473.

(3) Auwärter, W.; Weber-Bargioni, A.; Brink, S.; Riemann, A.; Schiffrin, A.; Ruben, M.; Barth, J. V. Controlled Metalation of Self-Assembled Porphyrin Nanoarrays in Two Dimensions. ChemPhysChem 2007, 8, 250-254.

(4) Gottfried, J. M.; Flechtner, K.; Kretschmann, A.; Lukasczyk, T.; Steinrück, H.-P. Direct Synthesis of a Metalloporphyrin Complex on a Surface. J. Am. Chem. Soc. 2006, 128, $5644-5645$. 
(5) Zhang, Y.-Q.; Kepčija, N.; Kleinschrodt, M.; Diller, K.; Fischer, S.; Papageorgiou, A. C.; Allegretti, F.; Björk, J.; Klyatskaya, S.; Klappenberger, F.; et al. Homo-Coupling of Terminal Alkynes on a Noble Metal Surface. Nat. Commun. 2012, 3, 1286.

(6) Shchyrba, A.; Wäckerlin, C.; Nowakowski, J.; Nowakowska, S.; Björk, J.; Fatayer, S.; Girovsky, J.; Nijs, T.; Martens, S. C.; Kleibert, A.; et al. Controlling the Dimensionality of On-Surface Coordination Polymers via Endo- or Exoligation. J. Am. Chem. Soc. 2014, $136,9355-9363$.

(7) Björk, J.; Stafström, S.; Hanke, F. Zipping Up: Cooperativity Drives the Synthesis of Graphene Nanoribbons. J. Am. Chem. Soc. 2011, 133, 14884-14887.

(8) Gao, H.-Y.; Held, P. A.; Knor, M.; Mück-Lichtenfeld, C.; Neugebauer, J.; Studer, A.; Fuchs, H. Decarboxylative Polymerization of 2,6-Naphthalenedicarboxylic Acid at Surfaces. J. Am. Chem. Soc. 2014, 136, 9658-9663.

(9) Otero, G.; Biddau, G.; Sánchez-Sánchez, C.; Caillard, R.; López, M. F.; Rogero, C.; Palomares, F. J.; Cabello, N.; Basanta, M. A.; Ortega, J.; et al. Fullerenes from Aromatic Precursors by Surface-Catalysed Cyclodehydrogenation. Nature 2008, 454, 865-868.

(10) Hayashi, H.; Yamaguchi, J.; Jippo, H.; Hayashi, R.; Aratani, N.; Ohfuchi, M.; Sato, S.; Yamada, H. Experimental and Theoretical Investigations of Surface-Assisted Graphene Nanoribbon Synthesis Featuring Carbon-Fluorine Bond Cleavage. ACS Nano 2017, 11, $6204-6210$.

(11) Zhou, X.-L.; White, J. M.; Koel, B. E. Chemisorption of Atomic Hydrogen on Clean and Cl-Covered Ag(111). Surf. Sci. 1989, 218, 201-210.

(12) Röckert, M.; Franke, M.; Tariq, Q.; Lungerich, D.; Jux, N.; Stark, M.; Kaftan, A.; Ditze, S.; Marbach, H.; Laurin, M.; et al. Insights in Reaction Mechanistics: Isotopic Exchange 
during the Metalation of Deuterated Tetraphenyl-21,23 D -Porphyrin on $\mathrm{Cu}(111)$. J. Phys. Chem. C 2014, 118, 26729-26736.

(13) Bronner, C.; Björk, J.; Tegeder, P. Tracking and Removing Br during the On-Surface Synthesis of a Graphene Nanoribbon. J. Phys. Chem. C 2015, 119, 486-493.

(14) Fan, Q.; Gottfried, J. M.; Zhu, J. Surface-Catalyzed C-C Covalent Coupling Strategies toward the Synthesis of Low-Dimensional Carbon-Based Nanostructures. Acc. Chem. Res. 2015, 48, 2484-2494.

(15) Gourdon, A. On-Surface Covalent Coupling in Ultrahigh Vacuum. Angew. Chem. Int. Ed. 2008, 47, 6950-6953.

(16) Klappenberger, F.; Zhang, Y.-Q.; Björk, J.; Klyatskaya, S.; Ruben, M.; Barth, J. V. OnSurface Synthesis of Carbon-Based Scaffolds and Nanomaterials Using Terminal Alkynes. Acc. Chem. Res. 2015, 48, 2140-2150.

(17) Crudden, C. M.; Horton, J. H.; Ebralidze, I. I.; Zenkina, O. V.; McLean, A. B.; Drevniok, B.; She, Z.; Kraatz, H.-B.; Mosey, N. J.; Seki, T.; et al. Ultra Stable Self-Assembled Monolayers of N-Heterocyclic Carbenes on Gold. Nat. Chem. 2014, 6, 409-414.

(18) Horcas, I.; Fernández, R.; Gómez-Rodríguez, J. M.; Colchero, J.; Gómez-Herrero, J.; Baro, A. M. WSXM: A Software for Scanning Probe Microscopy and a Tool for Nanotechnology. Rev. Sci. Instrum. 2007, 78, 013705.

(19) Diller, K.; Klappenberger, F.; Marschall, M.; Hermann, K.; Nefedov, A.; Wöll, C.; Barth, J. V. Self-Metalation of 2H-Tetraphenylporphyrin on Cu(111): An X-Ray Spectroscopy Study. J. Chem. Phys. 2012, 136, 014705.

(20) Buchner, F.; Flechtner, K.; Bai, Y.; Zillner, E.; Kellner, I.; Steinrück, H.-P.; Marbach, H.; Gottfried, J. M. Coordination of Iron Atoms by Tetraphenylporphyrin Monolayers and 
Multilayers on $\operatorname{Ag}(111)$ and Formation of Iron-Tetraphenylporphyrin. J. Phys. Chem. C 2008, 112, 15458-15465.

(21) Bai, Y.; Buchner, F.; Wendahl, M. T.; Kellner, I.; Bayer, A.; Steinruck, H.-P.; Marbach, H.; Gottfried, J. M. Direct Metalation of a Phthalocyanine Monolayer on $\operatorname{Ag}(111)$ with Coadsorbed Iron Atoms. J. Phys. Chem. C 2008, 112, 6087-6092.

(22) Mette, G.; Sutter, D.; Gurdal, Y.; Schnidrig, S.; Probst, B.; Iannuzzi, M.; Hutter, J.; Alberto, R.; Osterwalder, J. From Porphyrins to Pyrphyrins: Adsorption Study and Metalation of a Molecular Catalyst on Au(111). Nanoscale 2016, 8, 7958-7968.

(23) Li, J.; Wäckerlin, C.; Schnidrig, S.; Joliat, E.; Alberto, R.; Ernst, K.-H. On-Surface Metalation and 2D Self-Assembly of Pyrphyrin Molecules Into Metal-Coordinated Networks on Cu(111). Helv. Chim. Acta 2017, 100, e1600278.

(24) Graf, M.; Mette, G.; Leuenberger, D.; Gurdal, Y.; Iannuzzi Mauri, M.; Zabka, W.-D.; Schnidrig, S.; Probst, B.; Hutter, J.; Alberto, R.; et al. The Impact of Metalation on Adsorption Geometry, Electronic Level Alignment and UV-Stability of Organic Macrocycles on $\mathrm{TiO}_{2}$ (110). Nanoscale 2017, 9, 8756-8763.

(25) Diller, K.; Papageorgiou, A. C.; Klappenberger, F.; Allegretti, F.; Barth, J. V.; Auwärter, W. In Vacuo Interfacial Tetrapyrrole Metallation. Chem. Soc. Rev. 2016, 45, 1629-1656.

(26) Smykalla, L.; Shukrynau, P.; Zahn, D. R. T.; Hietschold, M. Self-Metalation of Phthalocyanine Molecules with Silver Surface Atoms by Adsorption on Ag(110). J. Phys. Chem. C 2015, 119, 17228-17234.

(27) Sperl, A.; Kröger, J.; Berndt, R. Controlled Metalation of a Single Adsorbed Phthalocyanine. Angew. Chem. Int. Ed. 2011, 50, 5294-5297. 
(28) Wiengarten, A.; Seufert, K.; Auwärter, W.; Ecija, D.; Diller, K.; Allegretti, F.; Bischoff, F.; Fischer, S.; Duncan, D. A.; Papageorgiou, A. C.; et al. Surface-Assisted Dehydrogenative Homocoupling of Porphine Molecules. J. Am. Chem. Soc. 2014, 136, 9346-9354.

(29) He, Y.; Garnica, M.; Bischoff, F.; Ducke, J.; Bocquet, M.-L.; Batzill, M.; Auwärter, W.; Barth, J. V. Fusing Tetrapyrroles to Graphene Edges by Surface-Assisted Covalent Coupling. Nat. Chem. 2016, 9, 33-38.

(30) Simonov, K. A.; Vinogradov, N. A.; Vinogradov, A. S.; Generalov, A. V.; Zagrebina, E. M.; Svirskiy, G. I.; Cafolla, A. A.; Carpy, T.; Cunniffe, J. P.; Taketsugu, T.; et al. From Graphene Nanoribbons on $\mathrm{Cu}(111)$ to Nanographene on $\mathrm{Cu}(110)$ : Critical Role of Substrate Structure in the Bottom-Up Fabrication Strategy. ACS Nano 2015, 9, 89979011.

(31) Lavallee, D. K.; Brace, J.; Winograd, N. X-Ray Photoelectron Spectra of NMethyltetraphenylporphyrins: Evidence for a Correlation of Binding Energies with MetalNitrogen Bond Distances. Inorg. Chem. 1979, 18, 1776-1780.

(32) Gurdal, Y.; Hutter, J.; Iannuzzi, M. Insight into (Co)Pyrphyrin Adsorption on Au(111): Effects of Herringbone Reconstruction and Dynamics of Metalation. J. Phys. Chem. C 2017, 121, 11416-11427.

(33) Shen, K.; Narsu, B.; Ji, G.; Sun, H.; Hu, J.; Liang, Z.; Gao, X.; Li, H.; Li, Z.; Song, B.; et al. On-Surface Manipulation of Atom Substitution between Cobalt Phthalocyanine and the $\mathrm{Cu}(111)$ Substrate. $R S C A d v \mathbf{2 0 1 7}, 7,13827-13835$. 
(34) Doyle, C. M.; Cunniffe, J. P.; Krasnikov, S. A.; Preobrajenski, A. B.; Li, Z.; Sergeeva, N. N.; Senge, M. O.; Cafolla, A. A. Ni-Cu Ion Exchange Observed for Ni(II)-Porphyrins on Cu(111). Chem. Commun. 2014, 50, 3447-3449.

(35) Lawton, E. A. The Thermal Stability of Copper Phthalocyanine. J. Phys. Chem. 1958, 62 $384-384$.

(36) Schreiver, I.; Hutzler, C.; Laux, P.; Berlien, H.-P.; Luch, A. Formation of Highly Toxic Hydrogen Cyanide upon Ruby Laser Irradiation of the Tattoo Pigment Phthalocyanine Blue. Sci. Rep. 2015, 5, 12915.

(37) Ciftlikli, E. Z.; Lee, E. Y. M.; Lallo, J.; Rangan, S.; Senanayake, S. D.; Hinch, B. J. Implementation of New TPD Analysis Techniques in the Evaluation of Second Order Desorption Kinetics of Cyanogen from $\mathrm{Cu}(001)$. Langmuir 2010, 26, 18742-18749.

(38) Joliat, E.; Schnidrig, S.; Probst, B.; Bachmann, C.; Spingler, B.; Baldridge, K. K.; von Rohr, F.; Schilling, A.; Alberto, R. Cobalt Complexes of Tetradentate, Bipyridine-Based Macrocycles: Their Structures, Properties and Photocatalytic Proton Reduction. Dalton Trans. 2016, 45, 1737-1745.

(39) Matena, M.; Stöhr, M.; Riehm, T.; Björk, J.; Martens, S.; Dyer, M. S.; Persson, M.; LoboCheca, J.; Müller, K.; Enache, M.; et al. Aggregation and Contingent Metal/Surface Reactivity of 1,3,8,10-Tetraazaperopyrene (TAPP) on $\mathrm{Cu}(111)$. Chem. - Eur. J. 2010, 16, 2079-2091.

(40) Wang, G.; Rühling, A.; Amirjalayer, S.; Knor, M.; Ernst, J. B.; Richter, C.; Gao, H.-J.; Timmer, A.; Gao, H.-Y.; Doltsinis, N. L.; et al. Ballbot-Type Motion of N-Heterocyclic Carbenes on Gold Surfaces. Nat. Chem. 2016, 9, 152-156. 
1

2

3

4

5

6

7

8

9

10

11

12

13

14

15

16

17

18

19

20

21

22

23

24

25

26

27

28

29

30

31

32

33

34

35

36

37

38

39

40

41

42

43

44

45

46

47

48

49

50

51

52

53

54

55

56

57

58

59

60

(41) Wang, H.; Dai, X.-J.; Li, C.-J. Aldehydes as Alkyl Carbanion Equivalents for Additions to Carbonyl Compounds. Nat. Chem. 2016, 9, 374-378. 


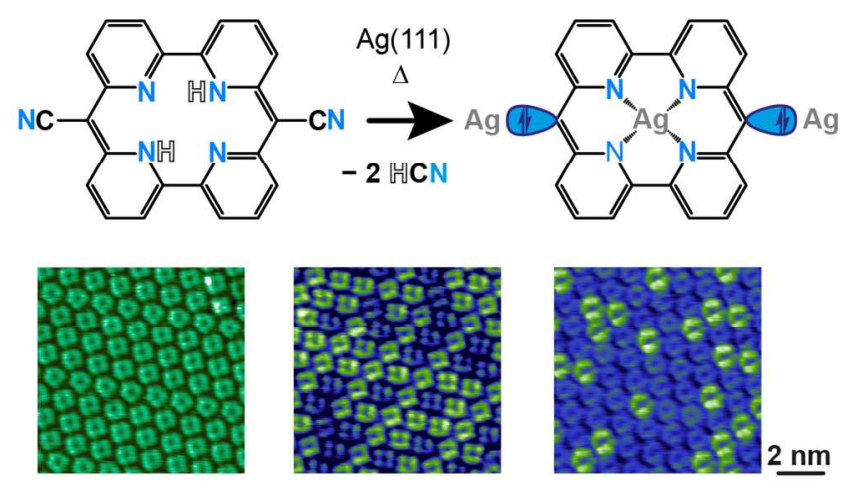

(TOC graphic: $8.5 \mathrm{~cm}$ width, $5 \mathrm{~cm}$ height) 


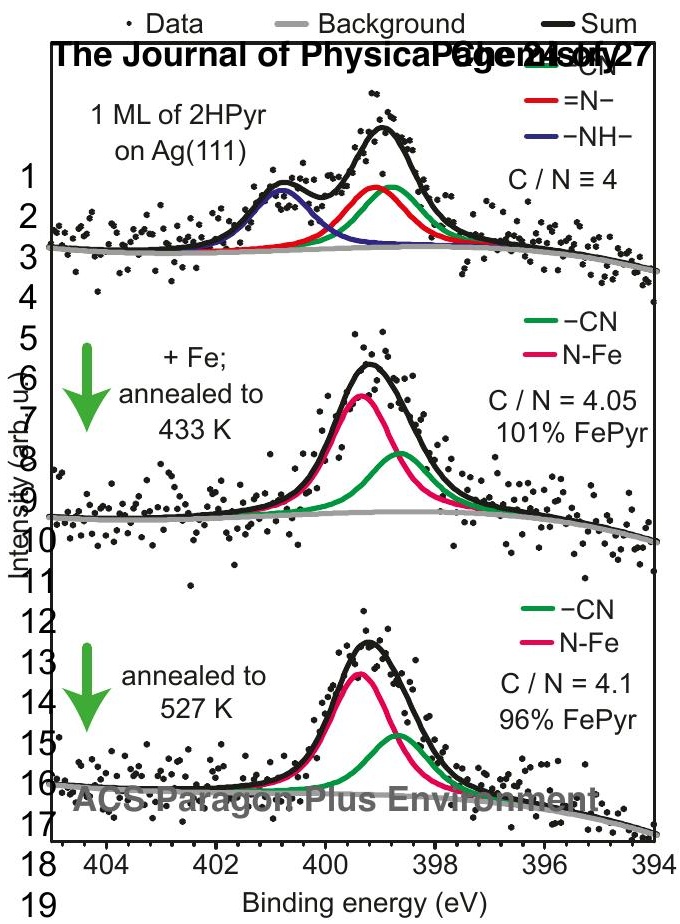


Increasing annealing temperature

\section{Page 25 of 27 The Journal of Physical Chemistry}
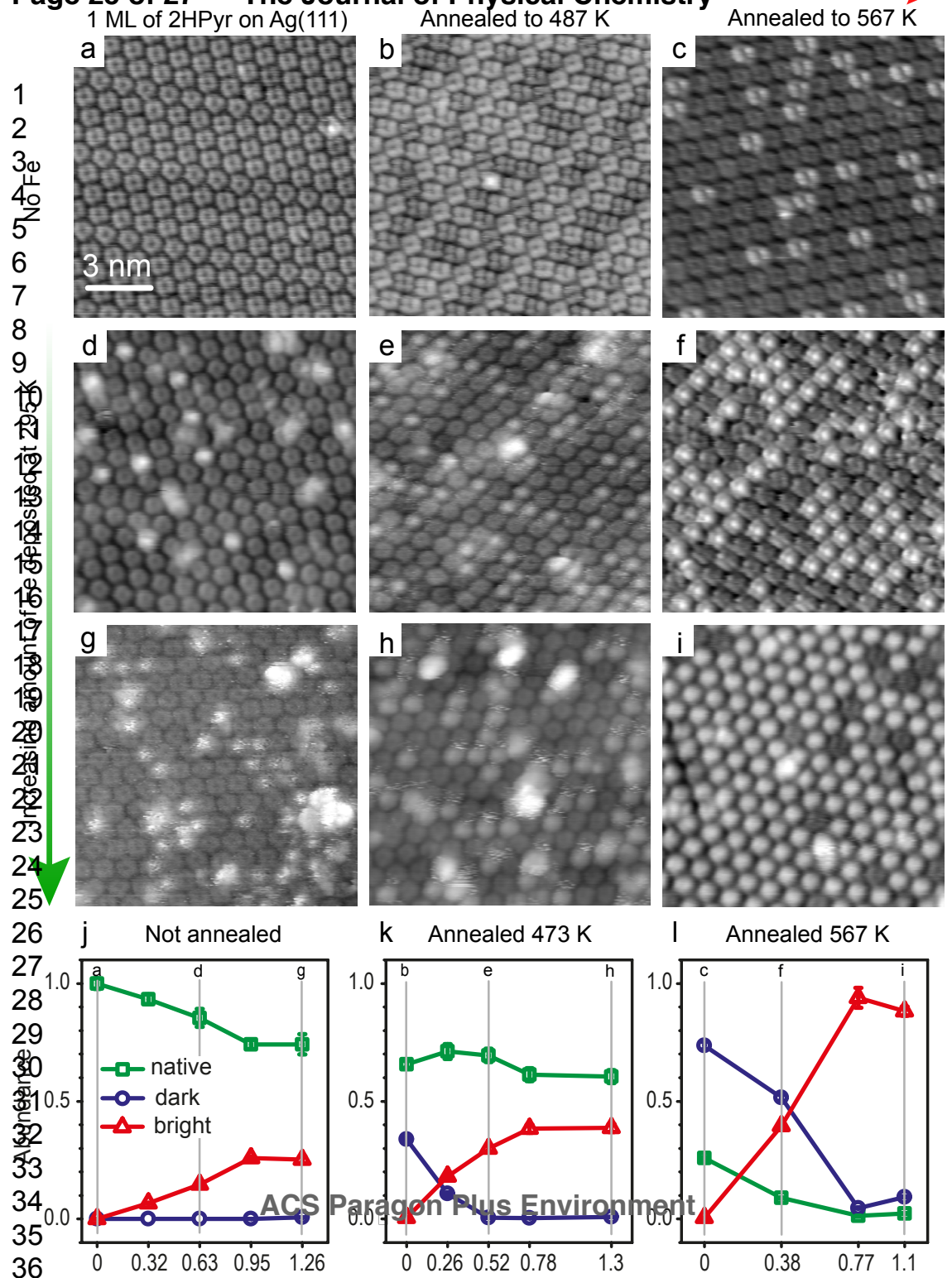

Fe atoms per molecule 


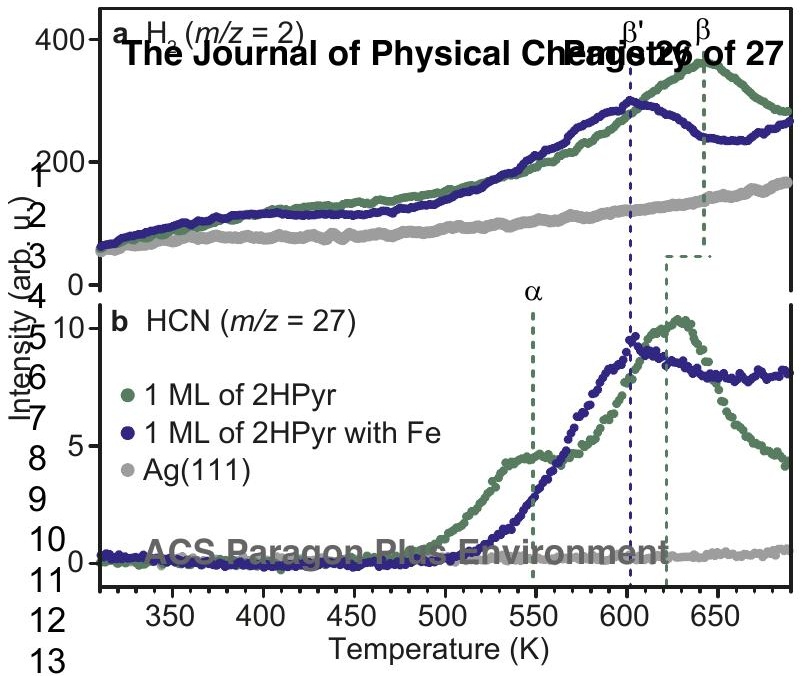




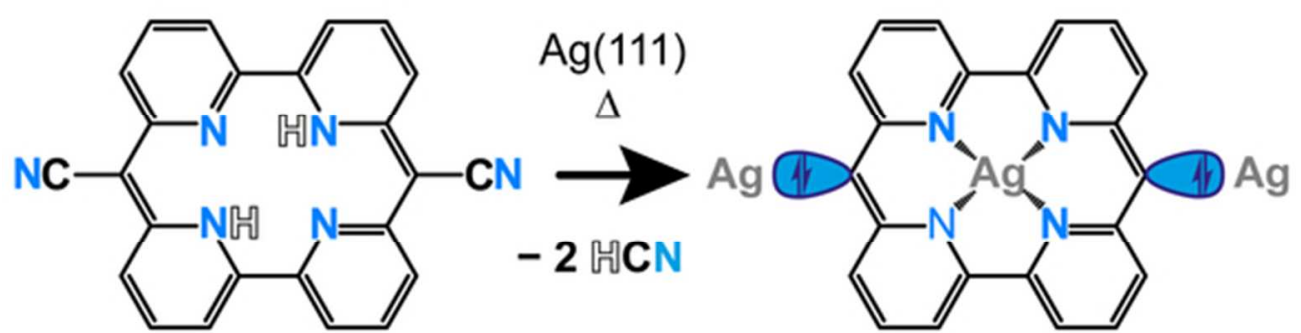
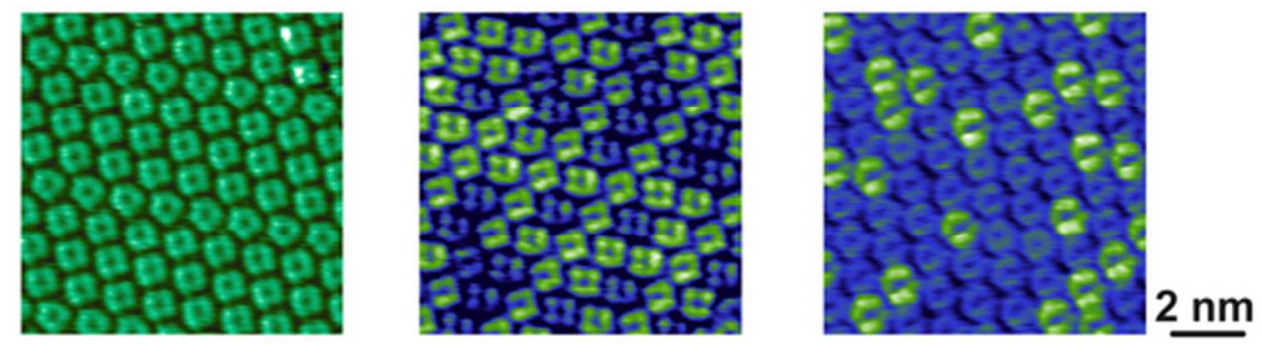

TOC

$50 \times 29 \mathrm{~mm}(300 \times 300 \mathrm{DPI})$ 